\title{
Attitude of Health Care Providers towards Adolescent Sexual and Reproductive Health Services in Developing Countries: A Systematic Review
}

\author{
Idesi Chilinda ${ }^{1}$, Georgina Hourahane ${ }^{2}$, Mercy Pindani ${ }^{1}$, Caroline Chitsulo ${ }^{1}$, Alfred Maluwa ${ }^{*}$ \\ ${ }^{1}$ Kamuzu College of Nursing, University of Malawi, Lilongwe Campus, Lilongwe, Malawi \\ ${ }^{2}$ Wales Centre for Evidence-Based Care, School of Nursing and Midwifery Studies, Cardiff University, \\ Cardiff, UK \\ Email: ${ }^{*}$ aomaluwa@kcn.unima.mw
}

Received 8 May 2014; revised 20 June 2014; accepted 9 July 2014

Copyright @ 2014 by authors and Scientific Research Publishing Inc.

This work is licensed under the Creative Commons Attribution International License (CC BY). http://creativecommons.org/licenses/by/4.0/

(c) (i) Open Access

\begin{abstract}
The aim of the review was to synthesise the best available evidence regarding attitude of health care providers towards adolescent sexual and reproductive health services in developing countries. The review was conducted following qualitative research method. An online search of $\mathrm{Cu}$ mulative Index to Nursing and Allied Health Literature (CINAHL), British Nursing Index (BNI), EMBASE and MEDLINE databases was conducted to identify relevant studies for the review. There were nine studies that met the inclusion criteria and these were critically assessed by two independent reviewers using the standardised Joanna Briggs Institute (JBI) critical appraisal forms. Data were extracted using the standardised JBI data extraction forms. A narrative synthesis was done on the findings. Key findings from the review indicate that unprofessional attitude of health care professionals and lack of youth friendly reproductive health services, inhibit adolescents from gaining access to sexual and reproductive health services in developing countries. It is recommended that youth friendly reproductive health services be provided to increase uptake of reproductive health services by adolescents.
\end{abstract}

\section{Keywords}

Adolescents, Reproductive Health, Systematic Review, Access to Health Services, Qualitative Studies, Barriers, Attitudes, Developing Countries

\footnotetext{
${ }^{*}$ Corresponding author.
}

How to cite this paper: Chilinda, I., Hourahane, G., Pindani, M., Chitsulo, C. and Maluwa, A. (2014) Attitude of Health Care Providers towards Adolescent Sexual and Reproductive Health Services in Developing Countries: A Systematic Review. Health, 6, 1706-1713. http://dx.doi.org/10.4236/health.2014.614203 


\section{Introduction}

Adolescents constitute about 20\% of the global population and 85\% of them are from developing countries [1]. An adolescent is described as an individual aged between ten and nineteen years [1] [2] and are regarded as a healthy generation. Consequently the adolescents are viewed as being an undeserved group when accessing Sexual and Reproductive Health Services (SRHS) in developing countries. The adolescents have reproductive health needs which require special attention. Hence, there is a need for SRHS that are accessible, appropriate and acceptable to significantly meet the reproductive health needs of the adolescents.

During the transition to adulthood some adolescents assume adult behaviours by engaging in sexual activity at an early age [3]. However, the majority of adolescents who engage in sexual activity do not practice safer sexual behaviours like the use of condoms which reduce the probability of pregnancy and acquisition of STIs [4]. Thus, although the adolescents have the intention to prevent early pregnancies and HIV and AIDS, they do not use SRHS consistently [5]. Inconsistent use of SRHS among the adolescents significantly contributes to high maternal mortality, the spread of HIV and AIDS and dropping out of school [6]. Efforts to reduce unsafe abortions, HIV and AIDS, STIs and early pregnancies can be successfully achieved by promoting safer sexual behaviours. In light of these complex negative health outcomes about adolescent RH, it is evident that SRH needs of adolescents are not addressed.

This review therefore seeks to explore attitudes of health care professionals towards adolescent SRHS in developing countries with the aim of improving access or usage of the services by adolescents, hence reducing unplanned pregnancies and STIs including HIV and AIDS.

\section{Methodology}

The review followed qualitative research methods and considered high quality studies of attitudes of health care providers towards adolescent SRHS in developing countries. Qualitative reviews explore beliefs and feelings of people and answer questions which are related to feasibility and effectiveness of interventions which quantitative reviews cannot provide [7]. A thorough and reproducible search strategy of both published and unpublished research studies was conducted. An initial search of the JBI of systematic reviews, Cochraine databases and Campbell Collaboration site were conducted to find out whether the topic for review was done before. This was followed by a three step search strategy. The first search was limited to CINAHL and Medline to identify all possible key words contained in the title and abstract. A comprehensive search of Medline, CINAHL, EMBASE and BNI was conducted to identify relevant studies for the review. Furthermore, backward and forward chaining was conducted to retrieve relevant studies. The search was limited to English language articles with abstracts. Time frame of studies was set to be from 1994 to 2012 to detect trends from the time SRH rights for all individuals including adolescents were declared in 1994 [8].

\section{Inclusion and Exclusion Criteria}

The studies that were included in the review were those that focussed on: 1) adolescents aged between 13 and 19 years and had accessed SRHS; 2) high quality qualitative, interpretative and critical research studies of adolescents' experiences in accessing SRHS in developing countries; 3) peer reviewed research articles published in English. The study excluded articles that were written in other languages other than English, those that used quantitative research methods, conference proceedings as well as studies with limited information. The phenomena of interest were the experiences of adolescents in gaining access to SRHS in developing countries.

\section{Data Collection}

A total of nine studies were evaluated for quality but seven were selected for further critical appraisal (Table 1). A detailed search strategy is shown in Table 2 and a flow chart of retrieved articles is presented in Figure 1. Critical appraisal of research studies was conducted to ascertain the methodological quality of the papers prior to inclusion in the review. The reviewers conducted regular meetings in Cardiff to develop this review. Any misunderstandings that arose from the reviewers were resolved through discussions. The quality of most studies was good.

According to JBI-QARI checklist for interpretive research, a series of questions and prompts were used to ascertain the quality of the articles for appraisal and included the following: congruence between the philosophical 
Table 1. Seven selected studies which were included in the current systematic review.

\begin{tabular}{|c|c|c|}
\hline Study & Sample & Methodology and data collection \\
\hline 1) Agampodi et al. (2008), Sri Lanka & $\begin{array}{l}\text { Convenience sample of } 32 \text { adolescent boys } \\
\text { and girls aged between } 17 \text { - } 19 \text { years }\end{array}$ & $\begin{array}{l}\text { Qualitative study: four focus group discussions } \\
\text { using a pretested focus group guide }\end{array}$ \\
\hline $\begin{array}{l}\text { 2) Wood and Jewkes (2006), South } \\
\text { Africa }\end{array}$ & $\begin{array}{l}35 \text { adolescent girls aged between } 14 \text { - } 20 \\
\text { years }\end{array}$ & $\begin{array}{l}\text { Qualitative study: } 35 \text { tape-recorded semi-structured } \\
\text { interviews, field work approach }\end{array}$ \\
\hline 3) Walter-Kippi et al. (2007), Uganda & $\begin{array}{l}4 \text { youth leaders, } 4 \text { managers of youth } \\
\text { organisations }\end{array}$ & Exploratory qualitative study: In-depth interviews \\
\hline 4) Khalaf et al. (2010), Jordan Region & $\begin{array}{l}\text { Convenience sample of } 33 \text { adolescent men } \\
\text { and } 27 \text { adolescent females aged between } \\
12 \text { - } 18 \text { years }\end{array}$ & $\begin{array}{l}\text { Qualitative study: six audio taped and transcribed } \\
\text { focus group discussions. }\end{array}$ \\
\hline 5) Langhaug et al. (2003), Zimbabwe & $\begin{array}{l}\text { Form } 3 \text { and } 4 \text { secondary students aged } \\
\text { between } 16 \text { - } 19 \text { years }\end{array}$ & $\begin{array}{l}\text { Qualitative study: Six focus group discussions tape } \\
\text { recorded and transcribed and direct observations }\end{array}$ \\
\hline 6) Regmi et al. (2010), Nepal & $\begin{array}{l}50 \text { adolescent boys and girls, purposefully } \\
\text { selected }\end{array}$ & $\begin{array}{l}\text { Qualitative study: Ten focus group discussions and } \\
\text { thirty-one tape recorded in depth interviews }\end{array}$ \\
\hline 7) Koster et al. (2003), Ghana & $\begin{array}{l}15 \text { - } 19 \text { year old adolescent boys and key } \\
\text { informants with knowledge in SRHS }\end{array}$ & $\begin{array}{l}\text { Qualitative study: Nine focus group discussions, } \\
\text { sixteen semi-structured interviews, eleven informal } \\
\text { interviews, structured observations and eight weeks } \\
\text { field work }\end{array}$ \\
\hline
\end{tabular}

Table 2. The search strategy used during the systematic review.

\begin{tabular}{cccccc}
\hline Database & Search date & Total number of hits & $\begin{array}{c}\text { Relevant articles with } \\
\text { title and abstract }\end{array}$ & Full texts retrieved & $\begin{array}{c}\text { Number included } \\
\text { for appraisal }\end{array}$ \\
\hline CINAHL & $1 / 07 / 12$ & 648 & 602 & 181 & 2 \\
EMBASE & $3 / 07 / 12$ & 3418 & 282 & 48 & 2 \\
MEDLINE & $5 / 07 / 12$ & 250 & 227 & 227 & 3 \\
BNI & $2 / 07 / 12$ & 1099 & 267 & 267 & 0 \\
Backward chaining & $1 / 07 / 12$ & & & 723 & 2 \\
Total & & 5415 & 1378 & & 9 \\
\hline
\end{tabular}

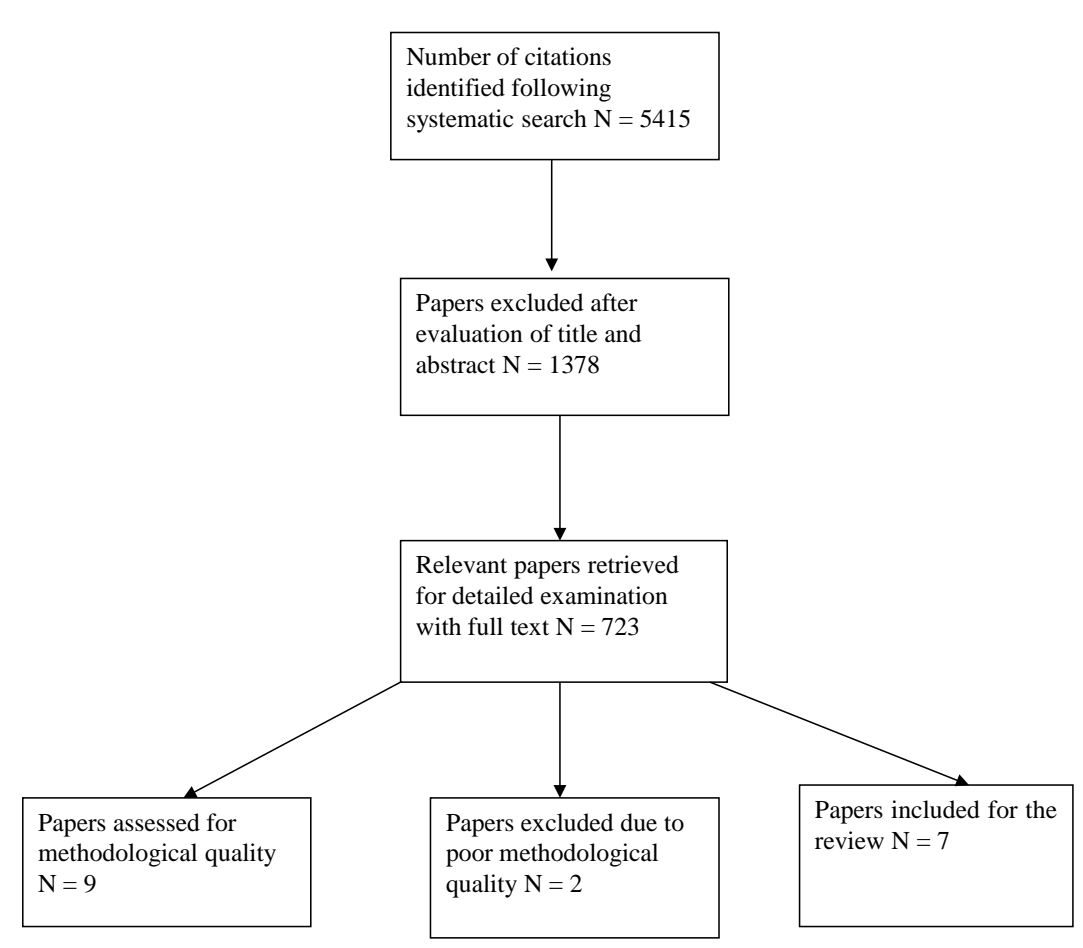

Figure 1. Flowchart of retrieved articles. 
perspective and research methodology, congruity between the research methodology and the methods used to collect data, congruity between the research methodology and the representation, analysis and interpretation of data. However, it was found that most of the research articles did not have a statement locating the researcher culturally or theoretically as advocated by the JBI. Furthermore, the influence of the researcher on the research and vice versa was unclear in most of the studies. A summary of the critical appraisal process was written to ensure trustworthiness of the review as recommended by Steward [9].

The seven studies that were selected for inclusion in this review were from seven developing countries; Zimbabwe, Uganda, Sri Lanka, Jordan Region, South Africa, Nepal and Ghana (Table 1). All the studies used qualitative approaches but using different schools of philosophy. Four studies utilised focus group discussions while two studies focussed on in-depth interviews to solicit ideas and information from adolescents. Adolescents were in the age range of 12 to 19 years, from various ethnic groups. The studies had diverse perspectives such as problems that adolescents faced when accessing SRHS and the ways of improving access to SRHS.

\section{Data Analysis}

Data were extracted from seven articles using the standardised JBI-QARI data extraction forms for interpretive research. The data were evaluated in terms of methodology, method of data collection used, intervention/phenomena of interest, setting, geographical, cultural, the participants involved, data analysis, and authors' conclusions which outlined the findings. In addition, study limitations, implications for research, education and practice were analysed to understand how the objectives of the studies were achieved. The first step of narrative synthesis in this review, involved conducting a preliminary synthesis of studies by providing an initial description of the results so that a pattern of data is described across them [10]. All the study findings were rated according to the JBI levels of credibility.

\section{Results}

A total of seven studies answered the review question and out of them forty five level one findings were extracted. The majority of the findings were represented by more than one illustration. Thirty of the findings were rated as unequivocal, six as credible and one as unsupported using JBI-QARI. Thematic analysis of the data generated two main themes which were stigma and discrimination by health care providers and lack of youth friendly reproductive health services.

\section{Stigma and Discrimination by Health Care Providers}

Three sub themes emerged from the stigma and discrimination main theme. These sub themes were; not right time for contraceptives, negative attitude of health care providers and health care providers' role conflict.

\subsection{Not Right Time for Contraceptives}

Health care providers were not comfortable to give contraceptive methods to adolescent girls as they were perceived to be “children". Health care providers felt that the early sexual debut of the adolescents is due to the easily availability of contraceptives in clinics. Health care providers were concerned with the high rate at which adolescents dropped out of school due to pregnancy. In addition most adolescents contracted sexually transmitted infections from their sexual activities which were encouraged by the use of contraceptives. Wood and Jewkes [[11], p.113] observe:

"It worries me a lot to see such small children getting involved in sexual activities at an early age exposing themselves to diseases, it touches me a lot."

Furthermore, adolescents reported that nurses often asked them "funny questions" such as: "did you tell your mother? ...why are you wearing a mini-skirt?”

One of the adolescent girls shared her experience (Wood and Jewkes, [[11], p. 113]:

"We just feel ashamed but we don't challenge them. Sometimes you may challenge them and find that you use words which may hurt them. Then next time you go there, you find they refuse to help you."

Langhaugh et al. [[12], p. 151] echoes that adolescents were labelled whenever they sought RH services at a clinic in Zimbabwe.

If one goes about inquiring about a certain disease, like STI or reproductive health, the nurses are quick to 
label you and suspect you have that disease or are pregnant.

\subsection{Attitude of Health Care Professionals}

The negative attitude of health care professionals was one of the recurrent concepts in four studies. Adolescents stated that health professionals were unsupportive and did not regard problems faced by the adolescents seriously. Consequently the adolescents were not given chance to discuss their RH issues. Langhaugh et al. [[12], p. 151] discussed:

I had a friend who once got an STI. He tried to get the condoms but the nurses could not allow him. Later he went with an STI and they shouted at him... yet they had denied him protective methods saying he was still young.

Additionally, it was reported that "someone I know was shouted at because she had an STI and was refused treatment” (Langhaugh et al. [[12], p. 151].

Similarly, Koster et al. [13] reported the experiences of adolescents in the Eastern region of Ghana. Poor attitude of health care workers and their lack of respect towards adolescents was the main concern. Koster et al. [[13], p. 6] discussed:

"Sometimes when you go, they look at your features and they feel that you are not of age. They ask a lot of questions, like; 'who sent you?' 'You are too small.' This is what they say and they send you away."

Furthermore, Agampodi et al. [[14], p. 5] expressed concern that the negative attitude of parents, teachers and the society creates a barrier to accessing the services because adolescents are treated as small kids.

"The doctor and the attendant are very busy to clear off the crowd. If you start long stories, they will ask you to cut it short. How can you cut it short when you do not know even how to start the story?”

One adolescent in Zimbabwe highlighted that nurses embarrassed them in public after seeking care and Langhaugh et al. [[12], p. 151] report:

Nurses may discuss young people's problems in public to embarrass the person especially if it's a girl.

A study conducted in South Africa by Wood and Jewkes [[11], p.114] using key informants reported that scolding of nurses was a major problem. It was emphasized that:

"Adolescents are verbally harassed by nurses and they described nurses as rude, short-tempered and arrogant. Adolescents are asked to bring their mother when coming for the service or seek parental permission first before the services are sought."

In Nepal, the negative attitude of health care professionals was also prevalent. Regmi et al. [[15], p.622] reports:

Once, I had a pain in my younanga [penis]. My friend advised me to visit the health post. When I dared to share my problem, the health service provider shouted at me. Later, I went to another hospital for check-up.

In the Jordan region, youths had similar bad experiences from health care professional. This is reported by Khalaf et al. [[16], p. 326]:

"Sometimes the healthcare providers are edgy and angry, so they might treat you bad, or tell you to come another time."

Additionally, "some of employees think that it is inappropriate to ask about such issues so they will not respect the person who asks about them".

\subsection{Health Care Providers' Role Conflict}

A study by Langhaugh et al. [[12], p. 151] revealed that nurses assume other unprofessional roles when adolescents seek reproductive health services at the facilities. This was a dilemma for nurses as it was difficult for them to differentiate parental role from professional role. The results are presented in this quote:

If a young person would come to me with a sexually transmitted disease, right away, I would remove myself from the position of the nurse and assume the role of the parent. Probably, the child would be the same age as my daughter or son.

\section{Lack of Youth Friendly Reproductive Health Services}

Three studies in the review identified that RH services were not youth-friendly. Koster et al. [13] found that adolescent boys prefer to be seen by male practitioners.

"We prefer males for counselling because we are all men and we all have the same thing" p. 7. 
Additionally, Koster et al. [14] reported that adolescents complained that health services were very expensive hence they could not afford to pay the costs.

A study by Khalaf et al. [16] indicated that most of the adolescents desired to have a big health facility which could be specific for the youth, attractive and accessible even during certain hours. This fact was quoted as follows:

"We need a centre where we will feel relaxed and cared for; we also want a nice, clean environment. We need visual aids for explanation and clarification of the information, with a caring healthcare provider".

Kippi et al. [[17], p. 387] also echoed these results and reported:

“The young people don't have enough people that they regard as people of authority... to give them information that they really trust..."

It was discussed by Regmi et al. [15] that adolescents in Nepal are not happy with RH services. Adolescents highlighted that most of the rural health facilities were not providing youth friendly RH services. Health care providers were also judgemental. The following is a quote from Regmi et al. [[15], p. 622]:

"I do not think that most young people go there for services because there are very few young service providers. How can we express our feelings to the people who are similar to our parents' age?"

Additionally, Regmi et al. [[15], p. 622] reported that adolescents are shouted at and reported:

"When I dared to share my problem, the health service provider shouted at me. Later, I went to another hospital for check-up."

Similarly Agampodi et al. [14] reported that adolescents preferred to be treated by young service providers and services which could be delivered during the evening, week end and not combined with maternal and child health services. Furthermore these adolescents preferred to be treated by a female doctor who could listen and understand their health problems. As such, adolescents opted for other alternative treatments like visiting the herbalist.

\section{Discussion}

The review has established that adolescents in developing countries are hindered from accessing SRHS due to stigma and discrimination by health care providers and lack of youth friendly reproductive health services. The issue of stigma and discrimination should not be overlooked when providing SRHS to adolescents. It was evident from the studies that adolescents were "labelled" and perceived as "children" whenever they wanted to access SRHS [12]. This then means that adolescents risk unwanted pregnancies and contracting STIs, including HIV and AIDS to "prove" that they are old enough to access SRHS. Furthermore health care providers were perceived as judgemental and unwelcoming. As such, adolescents were denied the services and asked to be accompanied by their parents [13]. Consequently adolescents sought treatment from other sources like herbalists. This review suggests that interventions that promote health seeking behaviours amongst adolescents should be an important component of RH.

Health professionals' negative attitudes toward adolescents (such as being shouted at) were evident in a number of studies as a hindrance to accessing SRHS. Thus poor attitude was reflected by the judgemental approach of the health providers. The unprofessional attitude of health care professionals may have serious health consequences on the lives of adolescents. As evidenced from these studies, many adolescents were driven away from health facilities when they sought preventive measures but later on sought unsafe abortion services when they became pregnant [18]. Unsafe abortions may lead to serious complications such as haemorrhage, sepsis and risk of mortality [19]. The efforts of reducing STIs and unwanted pregnancies amongst adolescents may thus have been hampered by negative health worker attitudes. Therefore there is a need for a deliberate effort by health care providers to reinforce positive attitudes towards adolescent reproductive health.

Lack of youth friendly RHS left many adolescents feeling ill-equipped to access SRHS [12] [13] [15]-[17]. As revealed from the FGDs the services were not youth friendly in that there were no male and female service providers to attend to male and female adolescents respectively. Additionally, the services were not integrated, clinics were not open during out of school hours and the waiting time was long. Services may become youth friendly by having service providers that are non-judgemental and respectful [16] [17]. In addition, health care workers should honour privacy and confidentiality of the adolescents [20]. Furthermore Lindberg et al. [21] recommends that SRHS should be provided in an integrated manner in a variety of settings so that during one clinic visit, the adolescent may also access other services rather than advising them to go back home and come another day. Therefore it is recommended that youth friendly RHS be integrated within the existing clinic struc- 
tures to significantly increase access to SRHS by adolescents in developing countries.

Results show that health care providers especially the nurses experienced a "role conflict" in the reproductive health care of the adolescents [12]. Nurses regarded adolescents as their own children and culturally they were not free to provide condoms and contraceptives to the youth [12]. This shows that there is interplay between cultural and professional contexts of RH for adolescents. The provision of RH care to adolescents is regarded as encouraging the adolescents to engage in early sexual activities. Despite this role conflict, adolescents have a right to access SRHS. Hence there is a need for health care providers to approve adolescent sexuality as a reality and assist them without a pragmatic approach. It is therefore suggested that critical thinking concerning cultural and moral dimensions regarding adolescent sexuality be emphasized to create an environment that tolerates adolescent sexuality.

\section{Conclusions}

Adolescent SRH remains a public health issue therefore it is important to note that adolescent sexuality is a reality and health care providers should accept it. Results show that stigma and discrimination of adolescent SRH remains a hindrance for adolescents to access RHS. The negative attitude of health care providers when attending to adolescent's RH needs has also adversely affected the adolescents' access to SRHS. Hence, there is a need to train health care providers to provide integrated youth-friendly SRHS. The health care providers should be friendly, non-judgemental and welcoming. Thus the staff should be specially trained to meet the RH needs of the youth. In addition, the units for providing services should be set apart so that privacy is maintained. Schools and clinics should provide information, education and counselling to adolescents regarding growth and development and maturation. As such, adolescents will be knowledgeable about sexual health and hence make informed choices.

In the communities, it is essential to promote awareness on the importance of early access to SRHS through appropriate community forums. This would help to de-stigmatise adolescent sexuality. Behaviour change interventions such as abstinence and condom use should be emphasized. The interventions can then assist in preventing the youths from contracting STIs and HIV and AIDS thus leading to a healthy generation.

\section{Limitations}

It is difficult to generalise the negative attitude of health care professionals and the stigma and discrimination as preventing adolescents gaining access to SRHS in developing countries because non English language studies were not included in the study.

\section{Acknowledgements}

This review was funded by Cardiff University in the United Kingdom as part of Master of Science studies for the senior author.

\section{Conflict of Interest}

No conflict of interest has been declared from the authors of this manuscript.

\section{References}

[1] UNFPA (2010) Improving Reproductive Health Services. http://www.unfpa.org/rh/services.htm

[2] Bearinger, L.H., Sieving, R., Ferguson, J. and Sharma, V. (2007) Global Perspectives on the Sexual and Reproductive Health of Adolescents: Patterns, Prevention, and Potential. Lancet, 369, 1220-1231. http://dx.doi.org/10.1016/S0140-6736(07)60367-5

[3] Mulye, T.P., Park, M.J., Nelson, C.D., Adams, S.H., Irwin, C.E. and Brindis, C.D. (2009) Trends in Adolescent and Young Adult Health in the United States. Journal of Adolescent Health, 45, 8-24. http://dx.doi.org/10.1016/j.jadohealth.2009.03.013

[4] World Health Organisation (2008) Unsafe Abortion. Global and Regional Estimates of the Incidence of Abortion and Associated Mortality. http://whqlibdoc.who.int/publications/2011/9789241501118_eng.pdf

[5] Fitzpatrick, E. and Walton-Moss, B. (2011) Barriers to Emergency Contraception for Adolescents. The Journal for Nurse Practitioners, 7, 282-286. http://dx.doi.org/10.1016/j.nurpra.2010.07.003 
[6] Speizer, I.S., Magnani, R.J. and Colvin, C.E. (2002) Qualitative Research in Nursing. Advancing the Humanistic Imperative. Lippincott Williams and Wilkins, New York.

[7] Wood, K. and Jewkes, R. (2006) Blood Blockages and Scolding Nurses: Barriers to Adolescent Contraceptive Use in South Africa. Reproductive Health Matters, 14, 109-118. http://dx.doi.org/10.1016/S0968-8080(06)27231-8

[8] World Health Organisation (2011) Family Planning: A Global Handbook for Providers. Evidence-Based Guidance Developed through Worldwide Collaboration. John Snow, Inc., Baltimore.

[9] Steward, B. (2004) Writing a Literature Review. British Journal of Occupational Therapy, 67, 495-500.

[10] Popay, J., Roberts, H., Sowden, A., Petticrew, M., Arai, L., Rodgers, M., Britten, N. and Duufy, S. (2006) Guidance on the Conduct of Narrative Synthesis in Systematic Reviews. http://www.lancaster.ac.uk/shm/research/nssr/research/dissemination/publications/NS Synthesis Guidance v1.pdf

[11] Wood, K. and Jewkes, R. (2006) Blood Blockages and Scolding Nurses: Barriers to Adolescent Contraceptive Use in South Africa. Reproductive Health Matters, 14, 109-118. http://dx.doi.org/10.1016/S0968-8080(06)27231-8

[12] Langhaug, L.F., Cowan, F.M., Nyamurera, T. and Power, R. (2003) Improving Young Peolpe’s Access to Reproductive Health Care in Rural Zimbabwe. AIDS Care, 15, 147-157. http://dx.doi.org/10.1080/0954012031000068290

[13] Koster, A., Kemp, J. and Offei, A. (2001) Utilisation of Reproductive Health Services by Adolescent Boys in the Eastern Region of Ghana. African Journal of Reproductive Health, 5, 40-49. http://dx.doi.org/10.2307/3583196

[14] Agampodi, S.B., Agampodi, T.C. and Piyaseeli, U.K.D. (2008) Adolescents Perception of Reproductive Health Care Services in Sri Lanka. BMC Health Services Research, 8, 98. http://dx.doi.org/10.1186/1472-6963-8-98

[15] Regmi, P., Teijlingen, E., Simkhada, P. and Acharya, D. (2010) Barriers to Sexual Health Services for Young People in Nepal. Journal of Health Population Nutrition, 28, 619-627. http://dx.doi.org/10.3329/jhpn.v28i6.6611

[16] Khalaf, I., Fathieh, A.M. and Froelicher, E. (2009) Youth Friendly Reproductive Health services in Jordan from the Perspective of the Youth: A Descriptive Qualitative Study. Scandinavian Journal of Caring Sciences.

[17] Kipp, W., Chacko, S., Laing, L. and Kabagambe, G. (2007) Adolescent Reproductive Health in Uganda: Issues Related to Access and Quality of Care. International Journal of Adolescent Health, 19, 383-393.

[18] Hung, S.L. (2010) Access to Safe and Legal Abortion for Teenage Women from Deprived Backgrounds in Hong Kong. Reproductive Health Matters, 18, 102-110. http://dx.doi.org/10.1016/S0968-8080(10)36527-X

[19] Haddad, L.B. and Nour, N.M. (2009) Unsafe Abortion: Unnecessary Maternal Mortality. Reviews in Obstetrics and Gynecology, 2, 122-126.

[20] Lindberg, C., Lewis-Sprill, C. and Crowner, R. (2006) Barriers to Sexual and Reproductive Health Care: Urban Male Adolescents Speak Out. Issues in Comprehensive Paediatric Nursing, 29, 73-88. http://dx.doi.org/10.1080/01460860600677577

[21] Ministry of Health and Population Malawi (2003) Management of Sexually Transmitted Infections Using Syndromic Management Approach. Guidelines for Service Providers, 2nd Edition, NAC, Lilongwe.

\section{Abbreviations}

SRHS, Sexual and Reproductive Health Services;

RH, Reproductive Health;

HIV, Human Immunodeficiency Syndrome;

AIDS, Acquired Immunodeficiency Syndrome;

STIs, Sexually Transmitted Infections;

JBI, Joanna Briggs Institute;

JBI-QARI, Joanna Briggs Institute-Qualitative Assessment and Review Instrument. 
Scientific Research Publishing (SCIRP) is one of the largest Open Access journal publishers. It is currently publishing more than 200 open access, online, peer-reviewed journals covering a wide range of academic disciplines. SCIRP serves the worldwide academic communities and contributes to the progress and application of science with its publication.

Other selected journals from SCIRP are listed as below. Submit your manuscript to us via either submit@scirp.org or Online Submission Portal.
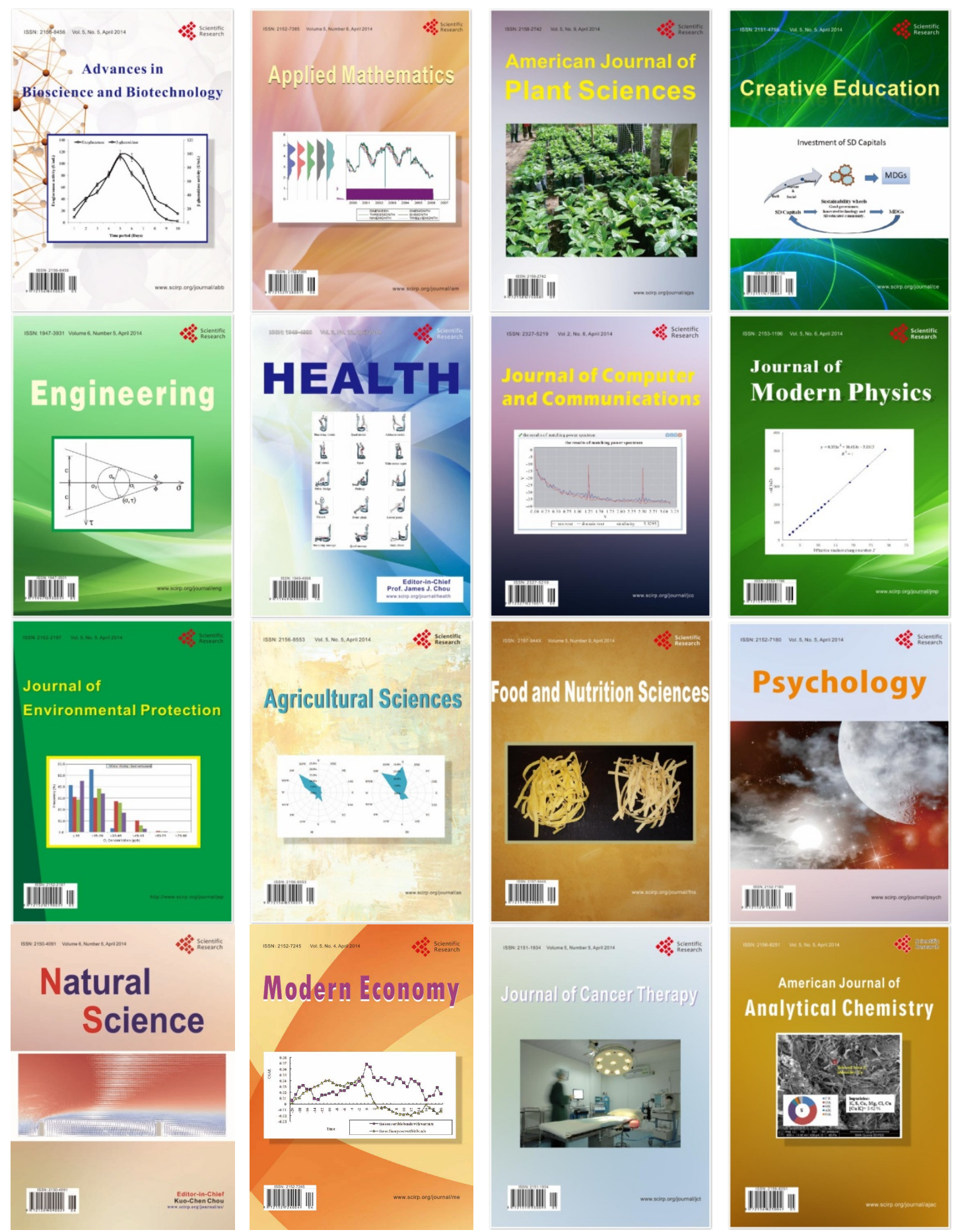